
ВОПРОСЫ ПРИМЕНЕНИЯ ИНГИБИТОРОВ

\title{
РЕНИН-АНГИОТЕНЗИН-АЛЬДОСТЕРОНОВОЙ СИСТЕМЫ
} Якубова Л. В., Кежун Л. В., Снежицкий В. А.

\author{
Гродненский государственный медицинский университет, Гродно, Беларусь
}

\begin{abstract}
Обзор современных публикаций свидетельствует, что у пащиентов с артериальной гипертензией (АГ) повышен риск тяжелого течения и смертельного исхода COVID-19. К основным патогенетическим механизмам, объясняющим ассочичаџию АГ с COVID-19, относят влияние коронавируса на работу ренин-ангиотензин-альдостероновой системы (РАAC), которая участвует в развитии и прогрессировании АГ. В обзоре представлены результаты ряда исследований с оценкой влияния применения иАПФ/БРА у пациентов с сердечно-сосудистыми заболеваниями на развитие и течение COVID-19. Результать международного анализа данных показали, что использование иАПФ/БРА у пациентов с АГ и COVID-19 ассочиированы с меньшими показателями общей смертности, а использование иАПФ, статинов и женский пол связаны с большей вероятностью выживания пациентов. Представлены данные по перспективным разработкам новых лекарственных средств, влияющих на работу РАAC.
\end{abstract}

Ключевые слова: COVID-19, артериальная гипертензия, ренин-ангиотензин-альдостероновая система

Для цитмиования: Якубова, Л. В. Клинические ассоичаџии коронавирусной инфекциии COVID-19 и артериальной гипертензии: патогенетические механизмы и дискуссионные вопросы применения ингибиторов ренин-ангиотензин-альдостероновой системы / Л. В. Якубова, Л. В. Кежун, В. А. Снежицкий // Журнал Гродненского государственного медииинского университета. 2020. T. 18, № 4. C. 349-357. http://dx.doi.org/10.25298/2221-8785-2020-18-4-349-357.

\section{введение}

Одно из ведущих мест по вкладу в смертность от сердечно-сосудистых заболеваний (СС3) занимает артериальная гипертензия (АГ), распространенность которой в мире составляет более 1,4 млрд человек и которая уносит более чем 28000 жизней ежедневно [1, 2]. В конце 2019 г. в Китае началась эпидемия коронавирусной инфекции, первоначально называемая 2019-nCoV и переименованная Всемирной организацией здравоохранения 11 февраля 2020 г. в пандемию «COVID-19» (coronavirus disease, 2019), официально признанную чрезвычайной ситуацией международного значения с высокой общепопуляционной смертностью. Новый коронавирус SARS-CoV-2, вызвавший пандемию COVID-19, представляет собой одноцепочечный РНК-содержащий вирус, который является седьмым членом семейства коронавирусов и к которому еще не сформирован приобретенный иммунитет $[3,4,5]$. Согласно имеющимся данным, наличие CC3 не ассоциировано с более высоким риском заражения SARS-CoV-2, однако ассоциировано с более высоким риском осложнений и летальности при присоединении данной инфекции у пациентов с СС3 [6, 7]. В условиях возникшей пандемии COVID-19 необходимо выделять пациентов с CC3 в группу высокого риска по неблагополучному течению и исходу новой коронавирусной инфекции.

В случаях смертельного исхода по COVID-19 в Китае пациенты с АГ составили 39,7\%, в то время как распространенность АГ в общей популяции взрослого населения составляет 23,2\% [8]. В Китае средняя летальность у пациентов с COVID-19 (n=72 314) составила 2,3\%, в то время как у пациентов с АГ летальность возросла до 6\%, а при наличии СС3 увеличилась до 10,5\% [9]. АГ встречалась чаще у пациентов с тяжелым течением COVID-19, требующим поддержки путем искусственной вентиляции лёгких, и у умерших, по сравнению с пациентами с легким течением заболевания [10]. Тяжелое течение с сопутствующей АГ имели 23,7\% из 1099 пациентов с подтвержденным диагнозом COVID-19 [11]. В другом китайском исследовании из 140 пациентов, госпитализированных с COVID-19, АГ была у 30\% [12].

В итальянской популяции общая смертность людей с подтвержденным COVID-19 составила $7,2 \%$, средний возраст умерших - 79 лет $[6,13]$. Распространенность АГ в популяции Италии составляет 25,9\% [14], в то время как среди умерших с подтвержденным COVID-19 АГ встречалась с частотой $73 \%[6,13]$.

В США, согласно данным сети эпиднадзора за госпитализацией, связанной с COVID-19 (COVIDNET), 89,3\% госпитализированных пациентов имели одно или несколько сопутствующих заболеваний, причем наиболее распространенными были АГ (49,7\%), ожирение $(48,3 \%)$, хронические заболевания лёгких $(34,6 \%)$, сахарный диабет (СД) $(28,3 \%)$ и СС3 $(27,8 \%)$ [13]. Такой же высокий процент коморбидности отмечен у госпитализированных пациентов с COVID-19 (n=5700) (средний возраст 63 года) в 12 больницах в Нью-Йорке, у которых наиболее распространенными сопутствующими заболеваниями были АГ $-56,6 \%$, ожирение $-41,7 \%$ и СД - 33,8\%. Уровень смертности был выше у мужчин, чем у женщин [15]. У пожилых людей наблюдались повышенные показатели госпитализации и смертности, связанные с COVID-19, а у большинства лиц, госпитализированных с COVID-19, имелись сопутствующие заболевания, чаще всего СС3 [13]. 
Таким образом, по данным ряда исследований в таких странах, как Китай, Италия, США, у пациентов с АГ и другими ССЗ повышен риск неблагоприятного течения и летального исхода при коронавирусной инфекции SARS-CoV-2.

\section{Роль ренин-ангиотензин-альдостероновой системы при COVID-19 и АГ}

Одним из ключевых патогенетических звеньев, связывающих коронавирусную инфекцию с ССЗ, вероятно, является ренин-ангиотензин-альдостероновая система (РААС). Известно, что активация РАAC - один из ведущих патогенетических механизмов формирования СС3, в частности АГ $[16,17,18,19,20,21]$. Каскад патологических процессов реализуется через основные компоненты этой системы (ренин, проренин, ангиотензин II (АТ II), альдостерон), которые как циркулируют в плазме крови (циркулирующая РАAC), так и синтезируются непосредственно в органах и тканях (сердце, почки, лёгкие, глаза, жировая ткань, поджелудочная железа), определяя поражение органов-мишеней гиперактивностью локальных (тканевых) PAAC. Структура РАAC представлена на рисунке.

Синтез АТ II - основного гормона РАAC происходит следующим образом. Ренин синтезируется в юкстагломерулярном аппарате почек из своего предшественника проренина и запускает преобразование ангиотензиногена в неактивный ангиотензин I (AT I). Далее ангиотензин-превращающий фермент (АПФ) преобразовывает АТ I в активный AT II, который оказывает свое воздействие через связь с двумя подтипами рецепторов: AT1 и АT2. АТ II связывается преимущественно с АТ1-рецепторами, локализованными на эндотелиальных и гладкомышечных клетках, что приводит к вазоконстрикторному, пролиферативному, провоспалительному эффектам и в целом - к развитию склеротических изменений тканей и сосудов, формированию дисфункции эндотелия и сосудистого ремоделирования. Именно через активацию AT1-рецепторов АТ II стимулирует секрецию альдостерона надпочечниками. Стимуляция АТ2-рецепторов приводит к прямо противоположному эффекту, однако их экспрессия у взрослого человека выражена меньше, чем экспрессия АТ1-рецепторов [22]. Следует отметить, что в последние два десятилетия представления о структуре РААС существенно усложнились и изменились. Были обнаружены ферменты, осуществляющие преобразования ангиотензиногена (катепсин $\mathrm{G}$, тонин, калликреин и др.) и АТ I (химаза и др.) в АT II, минуя АПФ. Роль АТ III и AT IV, которые также являются продуктами преобразования АT II, до конца не установлена.

Помимо классической РААС, осуществляющей свое действие через активацию АТ II и его рецепторы, обнаружена альтернативная РАAC, противостоящая атерогенному потенциалу АТ II при участии АПФ 2, который превращает AT I в Анг-(1-9), а AT II в Анг-(1-7), последний связывается с Маs-рецепторами [23, 24]. Кроме того, АПФ 2 может участвовать в гидролизе иных пептидов. Альтернативная работа РАAC связана с ослаблением эффектов АT II, сопровождающихся задержкой натрия, вазоконстрикцией и развитием фиброза, что обеспечивается распадом AT II до Анг-(1-7) и воздействием на Mas-рецепторы. Таким образом, АПФ 2 играет ключевую роль в РААС по реализации сосудорасширяющего, антипролиферативного и антиатеросклеротического эффектов [23, 24].

В свою очередь, SARS-CoV-2 использует АПФ 2 как функциональный рецептор для проникновения в основные клетки-мишени альвеолярного эпителия - альвелиоциты II типа, в цитоплазме которых происходит репликация вируса [25]. После эндоцитоза вирусной частицы происходит подавление экспрессии АПФ 2 на

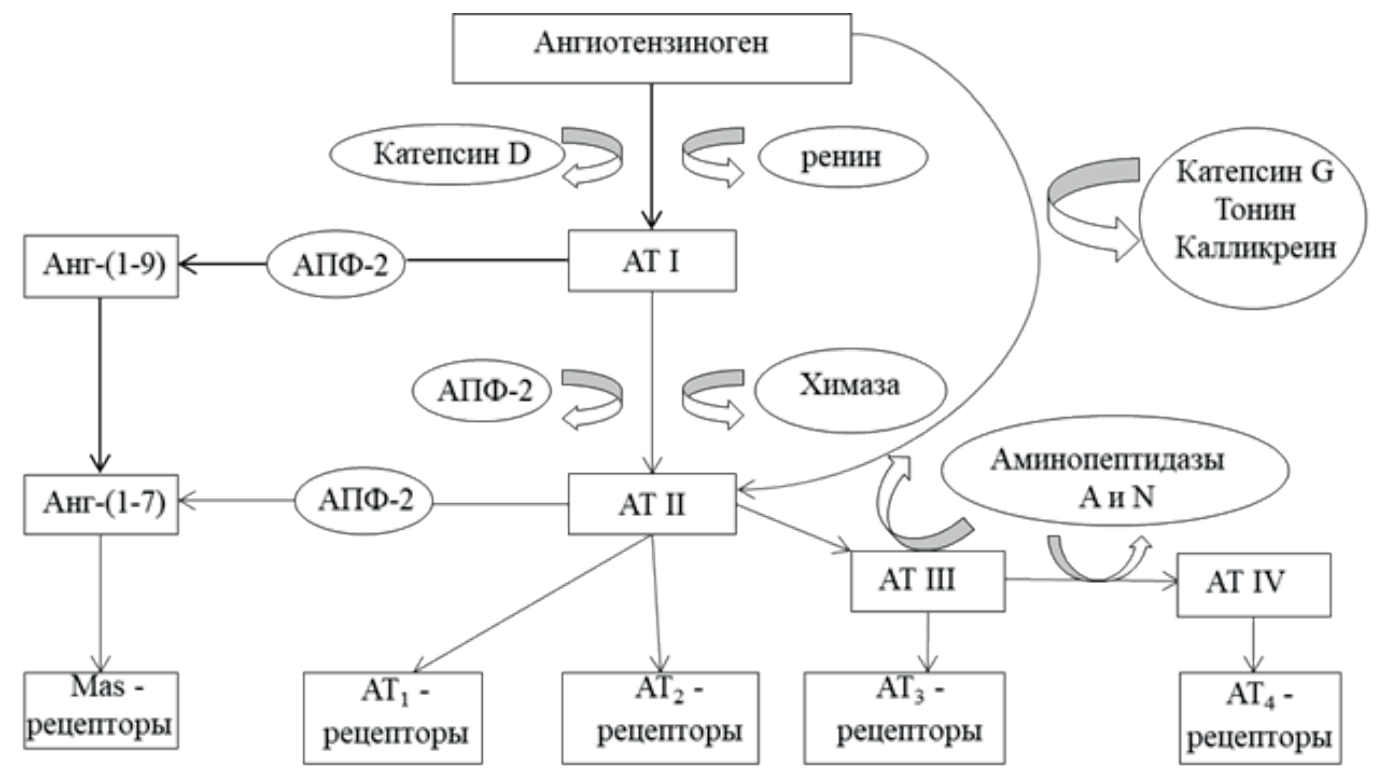

Рисунок-Современная структура ренин-ангиотензин-альдостероновой системы

Figure - Modern structure of the renin-angiotensin-aldosterone system 
поверхности клеточной мембраны, приводящее к неконтролируемому накоплению АТ II и активации РААС.

Местная активация РААС может опосредовать повреждение лёгочной ткани при вирусной инфекции. Действие вируса вызывает повышение проницаемости клеточных мембран и усиленный транспорт жидкости, богатой альбумином, в интерстициальную ткань лёгкого и просвет альвеол. При этом разрушается сурфактант, что ведет к коллапсу альвеол, в результате резкого нарушения газообмена развиваются острый респираторный дистресс-синдром, тяжелые пневмонии.

Проведенные ранее генетические и экспериментальные исследования подтверждают, что АПФ 2 является функциональным рецептоpoм SARS-CoV, который может вызвать тяжелый острый респираторный дистресс-синдром (SARS) [26, 27]. Так, в экспериментальном исследовании показано, что при инфицировании мышей SARS-CoV происходит снижение экспрессии АПФ 2. Авторы пришли к заключению, что АПФ 2 защищает лёгкие мышей от развития SARS и его течение может быть ослаблено путем блокирования пути АТ-Анг [26, 27].

\section{Роль провоспалительных цитокинов при COVID-19 и $A \Gamma$}

Наряду с активаций PAAC, SARS-CoV-2 способен вызывать гипериммунный ответ, при котором происходит неконтролируемая продукция провоспалительных цитокинов (ИЛ-2, ИЛ6, ИЛ-7, ФНО- $\alpha$ ), получившая название «цитокиновый шторм», в результате чего возникает повреждение лёгочной ткани, других органов и систем [28, 29]. По данным экспериментальных $[30,31]$ и клинических исследований [32], ряд цитокинов участвуют в патогенетических механизмах формирования АГ. Например, ИЛ-6, который тесно связан с клиническими исходами COVID-19 [33], является одним из ключевых цитокинов, регулирующих иммуновоспалительные реакции при АГ [34]. Кроме того, установленной особенностью COVID-19 является нарушение Т-клеточного иммунитета, снижение общего количества Т-клеток, лимфоцитов CD4+ и CD8+ [35]. В свою очередь недавнее исследование с оценкой данных биобанка Великобритании показало причинную связь количества лимфоцитов с систолическим и диастолическим артериальным давлением [36]. Иммунная дисрегуляция, по-видимому, - еще одно патогенетическое звено взаимосвязи COVID-19 и АГ, обуславливающая потенциально более тяжелое течение коронавирусной инфекции, что требует дальнейшего изучения.

\section{Влияние медикаментозной блокады РАAC на течение и исходы COVID-19}

Блокаторы РАAC - ингибиторы АПФ (иАПФ) и блокаторы рецепторов АТ II (БРА), относящиеся к одной из пяти основных групп антигипертензивных препаратов, с наибольшей частотой используются в терапии АГ и других СС3. В настоящее время продолжает обсуждаться во- прос о способности иАПФ/БРА индуцировать повышенную экспрессию АПФ 2. Применение данных групп препаратов может, с одной стороны, повышать вероятность развития вирусной инфекции и прогрессирования вирус-индуцированного заболевания, с другой стороны, способствовать снижению патогенного воспаления. На сегодняшний день ведущие кардиологические сообщества - Европейское общество кардиологов (ESC), Американская кардиологическая ассоциация (АНА), Американское общество по сердечной недостаточности (HFSA), Американский колледж кардиологии (АСC) и Международное общество по борьбе с гипертонией (ISH) - настоятельно рекомендуют пациентам с CC3 продолжать прием иАПФ и БРА при заболевании COVID-19 [37]. Главным аргументом в пользу этой рекомендации стало отсутствие достаточных данных, свидетельствующих о неблагоприятном влиянии иАПФ/БРА на прогноз COVID-19 [38].

Эпидемиологические, демографические, клинические и лабораторные данные ретроспективного одноцентрового анализа пациентов с COVID-19 и АГ показали, что те, кто получал либо иАПФ/БРА, либо другую антигипертензивную терапию, имели схожие показатели артериального давления. Однако в группе иАПФ/ БРА были значительно более низкими концентрации С-реактивного белка $(\mathrm{p}=0,049)$ и прокальцитонина $(\mathrm{p}=0,008)$. Кроме того, значительно меньшая доля пациентов в критическом состоянии $(9,3 \%$ против $22,9 \% ; \mathrm{p}=0,061)$ и более низкая смертность (4,7\% против $13,3 \%$; $=0,216)$ наблюдалась в группе пациентов, получавших иАПФ/БРА, по сравнению с группой пациентов, не получавших иАПФ/БРА. Таким образом, результаты данных исследований могут свидетельствовать в пользу применения иАПФ/БРА у пациентов с COVID-19 и АГ [39]. Другой ретроспективный анализ ассоциаций внутрибольничного применения иАПФ/БРА с общей смертностью у 1128 пациентов с COVID-19 и АГ показал, что коэффициент общей смертности ниже в группе пациентов, у которых проводилась терапия с применением иАПФ/БРА, по сравнению с группой пациентов, у которых иАПФ/БРА не применялись $(3,7 \%$ против 9,8\%; $=0,01)$. Это дает основания предполагать органопротективный эффект данных лекарственных средств у пациентов, инфицированных SARS-CoV-2 [40].

G. Mancia и соавт. оценивали связь между использованием блокаторов РАAC и риском COVID-19 в исследовании случай-контроль с участием 6272 пациентов с подтвержденным диагнозом COVID-19 в Ломбардии. Контрольную группу составили 30759 человек, сопоставимые по полу, возрасту и месту проживания. Пациенты c COVID-19 имели более высокую распространенность СС3 и чаще использовали БРА (22\%) и иАПФ $(23,1 \%)$, чем лица контрольной группы $(19,2$ и $21,4 \%$, соответственно). Статистический анализ показал, что применение БРА или иАПФ не имело какой-либо связи с COVID-19 как среди пациентов в целом (отношение шан- 
сов (ОШ) 0,95 (95\% доверительный интервал (ДИ) 0,86-1,05) для БРА и ОШ=0,96 (95\% ДИ 0,87-1,07) для иАПФ), так и среди пациентов с тяжелым течением или летальным исходом заболевания (ОШ=0,83 (95\% ДИ 0,63-1,10) для БРА и ОШ=0,91 (95\% ДИ 0,69-1,21) для иАПФ. Таким образом, в исследовании не получено доказательств того, что иАПФ или БРА ассоциированы с частотой развития и неблагоприятного течения COVID-19 [41].

При анализе электронных медицинских карт, выполненном в Нью-Йоркском университете у пациентов с АГ $(\mathrm{n}=4357)$ с положительным $(n=2573)$ и отрицательным $(n=1784)$ тестом COVID-19, также не обнаружено связи приема антигипертензивных препаратов с увеличением вероятности положительного теста на COVID-19 или риска тяжелого течения данной инфекции [42].

Особый интерес представляют результаты международного анализа данных, основанные на включении 8910 случаев госпитализаций па-

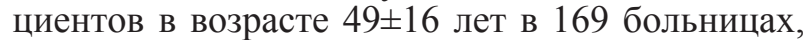
расположенных в 11 странах Азии, Европы и Северной Америки [43]. Независимыми предикторами роста летальности от COVID-19 (таблица) являлись: возраст >65 лет, ишемическая болезнь сердца, хроническая сердечная недостаточность, аритмии, хроническая обструктивная болезнь лёгких, курение в настоящее время. В то время как женский пол, использование иАПФ и статинов были связаны с большей вероятностью выживания пациентов. При этом связи с применением БРА не обнаружено.

CC3 сопровождаются развитием сердечной недостаточности. Результаты исследований свидетельствуют, что содержание АПФ 2 увеличива- ется при сердечной недостаточности [44]. Представляют интерес данные, полученные в ходе исследования BIOSTAT-CHF из 11 европейских стран, по измерению концентрации АПФ 2 у мужчин (n=1485, средний возраст 69 лет) и женщин $(\mathrm{n}=537$, средний возраст 72 года) с сердечной недостаточностью, составивших основную группу. Группой контроля была сопоставимая независимая выборка из Шотландии, состоявшая из 1123 мужчин и 575 женщин с сердечной недостаточностью. Так, в основной группе средняя концентрация АПФ 2 в крови составила 5,38 у мужчин и 5,09 у женщин $(\mathrm{p}<0,001)$, в группе контроля $-5,46$ и 5,16, соответственно $(\mathrm{p}<0,001)$. В двух независимых группах самым сильным предиктором повышенной концентрации АПФ 2 в крови являлся мужской пол (estimate $=0,26$; $\mathrm{p}<0,001 ;$ и 0,$19 ; \mathrm{p}<0,001$, соответственно). В основной группе иАПФ, БРА, антогонисты минералокотрикоидных рецепторов не были связаны с более высокими концентрациями АПФ 2 в плазме крови. В группе контроля иАПФ (estimate $=-0,17 ; \mathrm{p}=0,002$ ) и БРА (estimate $=-0,15$; $\mathrm{p}=0,03$ ) были связаны с более низкими концентрациями АПФ 2 в крови, антагонисты минералокортикоидных рецепторов были связаны с более высокими концентрациями АПФ 2 в крови (estimate $=0,11 ; \mathrm{p}=0,04)$, однако эта связь была слабой. В исследовании также говорится о тканеспецифичности выработки АПФ 2 у мужчин в яичках и семенниках и, соответственно, о его более высоком уровне. Это может частично объяснить, почему в условиях пандемии COVID-19 у мужчин выше частота развития SARS-CoV-2 и смертность при этой инфекции [45]. Однако результаты данного исследования имеют некоторое ограничение в интерпретации, поскольку оно выполнено на пациентах без COVID-19. Тем не менее, данное исследование весьма актуально в ситуации пандемии COVID-19, поскольку пациенты с сердечной недостаточностью - уязвимая группа по коронавирусной инфекции и составляют, по данным в США, до 40\%. В Италии же $70 \%$ пациентов, умерших от COVID-19, мужчины, в основном пожилого возраста [46].

\section{Перспективные исследования}

В настоящее время создан человеческий рекомбинантный растворимый АПФ 2 (hrs АПФ 2), названный APN01, который уже проходит вторую фазу клинических испытаний оценки его способности лечить от пневмонии, 
вызванной SARS-CoV-2. Предполагается, что APN01, имитируя человеческий АПФ 2, позволит противодействовать болезни. Во-первых, при связывании вируса с растворимым APN01, вместо АПФ 2, на клеточной поверхности он больше не сможет заразить клетки. Во-вторых, APN01, действуя как АПФ 2, уменьшает воспалительные реакции не только в лёгких, но и в других органах, тем самым способствует защите от повреждения $[47,48,49]$. Более глубокое понимание структуры и работы РААС открыло новые возможности в разработке лекарственных средств, направленных на активацию направления АПФ $2 \rightarrow$ Анг(1-7) $\rightarrow$ Mas-рецепторы для противодействия работе АПФ $2 \rightarrow$ AT II $\rightarrow$ AT1 рецепторы. Данные исследования находятся на доклинических и ранних клинических стадиях разработки, включая исследование новых низкомолекулярных ингибиторов и агонистов/антагонистов рецепторов, менее традиционных стратегий, таких как генная терапия для подавления ангиотензиногена на уровне РНК, рекомбинантный белок АПФ 2 и новые биспецифичные дизайнерские пептиды [50]. Испытания новых лекарственных средств, влия-

\section{Лumepamypa}

1. Global, regional, and national comparative risk assessment of 84 behavioural, environmental and occupational, and metabolic risks or clusters of risks for 195 countries and territories, 1990-2017: a systematic analysis for the Global Burden of Disease Study 2017 / J. D. Stanaway [et al.] // Lancet. - 2018. - Vol. 392, iss. 10159. - P. 1923-1994. doi: 10.1016/S0140-6736(18)32225-6.

2. Global Disparities of Hypertension Prevalence and Control: A Systematic Analysis of Population-based Studies from 90 Countries / K. T. Mills [et al.] // Circulation. 2016. - Vol. 134, iss. 6. - P. 441-450. - doi: 10.1161/ CIRCULATIONAHA.115.018912.

3. Epidemiology, causes, clinical manifestation and diagnosis, prevention and control of coronavirus disease (COVID-19) during the early outbreak period: a scoping review / S. P. Adhikari [et al.] // Infectious Diseases of Poverty. - 2020. - Vol. 9, iss. 1. - P. 29. - doi: 10.1186/ s40249-020-00646-x.

4. Sifuentes-Rodríguez, E. COVID-19: The outbreak caused by a new coronavirus / E. Sifuentes-Rodríguez, D. Palacios-Reyes // Boletin medico del Hospital Infantil de Mexico. - 2020. - Vol. 77, iss. 2. - P. 47-53. - doi: 10.24875/BMHIM.20000039.

5. The SARS-CoV-2 outbreak: what we know / D. Wu [et al.] // International Journal of Infectious Diseases. - 2020. - Vol. 94. - P. - 44-48. - doi: 10.1016/j.ijid.2020.03.004.

6. Hypertension, the renin-angiotensin system, and the risk of lower respiratory tract infections and lung injury: implications for COVID-19 / R. Kreutz [et al.] // Cardiovascular Research. - 2020. - cvaa097. - doi: 10.1093/cvr/cvaa097.

7. Potential Effects of Coronaviruses on the Cardiovascular System: A Review / M. Madjid [et al.] // JAMA. Cardiology. - 2020. - doi: 10.1001/jamacardio.2020.1286.

8. Status of hypertension in China: results from the China Hypertension Survey, 2012-2015 / Z. Wang [et al.] // Circulation. - 2018. - Vol. 137, iss. 22. - P. 2344-2356. doi: 10.1161/CIRCULATIONAHA.117.032380. ющих на работу РАAC, - возможность к повышению эффективности терапии АГ и других СС3.

\section{Заключение}

Таким образом, обзор международных научных данных показывает, что у пациентов с АГ повышен риск тяжелого течения и смертельного исхода COVID-19. Одним из патогенетических механизмов COVID-19 является дисрегуляция РААС, сопровождающаяся повышением выработки и активности локального АT II в лёгочной ткани ввиду изменения экспрессии АПФ 2. Прием иАПФ/БРА у пациентов с АГ и COVID-19 ассоциирован с меньшими показателями общей смертности и в настоящее время отсутствуют убедительные данные по поводу того, что у пациентов с АГ, принимающих иАПФ/ БРА, повышен риск инфицирования COVID-19. Возможная предрасположенность к развитию коронавирусной инфекции при генетической детерминированности различной экспрессии АПФ 2, в том числе и у пациентов с АГ, требует дальнейших клинических и экспериментальных исследований.

9. The epidemiological characteristics of an outbreak of 2019 novel coronavirus diseases (COVID-19) in China / S. Bai [et al.] // Zhonghua Liu Xing Bing Xue Za Zhi. 2020. - Vol. 41, iss. 2. - P. 145-151. - doi: 10.3760/cma.j. issn.0254-6450.2020.02.003.

10. Singh, A. K. Comorbidities in COVID-19: Outcomes in hypertensive cohort and controversies with renin angiotensin system blockers / A. K. Singh, R. Gupta, A. Misra // Diabetology \& Metabolic Syndrome. 2020. - Vol. 14, iss. 4. - P. 283-287. - doi: 10.1016/j. dsx.2020.03.016.

11. Clinical characteristics of coronavirus disease 2019 in China / W. Guan [et al.] // New England Journal of Medicine. - 2020. - № 382. - P. 1708-1720. - doi: 10.1056/NEJMoa2002032.

12. Clinical characteristics of 140 patients infected by SARSCoV-2 in Wuhan, China / J.-j. Zhang [et al.] // Allergy. - 2020. - Jul 75(7). - P. 1730-1741. - doi: 10.1111/ all.14238.

13. Hospitalization Rates and Characteristics of Patients Hospitalized with Laboratory-Confirmed Coronavirus Disease 2019 - COVID-NET, 14 States, March 1-30, 2020 / S. Garg [et al.] // Morbidity and Mortality Weekly Report. - 2020. - Vol. 69, iss.15. - P. 458-464. - doi: 10.15585/ mmwr.mm6915e3.

14. Prevalence and control of hypertension in the general practice in Italy: updated analysis of a large database / G. Tocci [et al.] // Journal of Human Hypertension. - 2017. - Vol. 31, iss. 4. - P. 258-262. - doi: 10.1038/jhh.2016.71.

15. Presenting Characteristics, Comorbidities, and Outcomes Among 5700 Patients Hospitalized with COVID-19 in the New York City Area / S. Richardson [et al.] // JAMA. 2020. - Vol. 323, iss. 20. - P. 2052-2059. - doi: 10.1001/ jama.2020.6775.

16. Paul, M. Physiology of local renin-angiotensin systems / M. Paul, A. P. Mehr, R. Kreutz // Physiological Reviews. - 2006. - Vol. 86, iss. 3. - P. 747-803. doi: 10.1152/ physrev.00036.2005.

17. Romero, C. Novel RAAS agonists and antagonists: clinical applications and controversies / C. Romero, M. Orias, M. 
Weir // Nature Reviews Endocrinology. - 2015. - Vol. 11, iss. 4. - P. 242-252. - doi: 10.1038/nrendo.2015.6.

18. Ferrario, C. M. Renin angiotensin aldosterone inhibition in the treatment of cardiovascular disease / C. M. Ferrario, A. E. Mullick // Pharmacology Research. - 2017. - Vol. 125, (pt. A). - P. 57-71. - doi: 10.1016/j.phrs.2017.05.020

19. Якубова, Л. В. Изменение активности ренина плазмы и функции эндотелия у лиц с артериальной гипертензией при терапии с включением ингибитора ангиотензинпревращающего фермента и холекальциферола / Л. В. Якубова, Л. В. Кежун, О. В. Семячкина-Глушковская // Рецепт. - 2017. T. 20, № 6. - С. 568-577.

20. Кежун, Л. В. Роль ренин-ангиотензин-альдостероновой системы и витамина $\mathrm{D}$ в развитии артериальной гипертензии у женщин в перименопаузальном периоде / Л. В. Кежун, Л. В. Янковская // Журнал Гродненского государственного медицинского университета. - 2013. - № 1 (41). - С. 14-17.

21. Кежун, Л. В. Активность ренина плазмы функции эндотелия и статус витамина D женщин с артериальной гипертензией в пременопаузальном и раннем постменопаузальном периодах / Л. В. Кежун, Л. В. Янковская // Журнал Гродненского государственного медицинского университета. - 2014. № 4 (48). - C. 37-42.

22. Angiotensin receptors: distribution, signaling and function / D. T. Dihn [et al.] // Clinical Science. - 2001. - Vol. 100, iss. 5. - P. 481-492.

23. Effect of angiotensin-converting enzyme inhibition and angiotensin II receptor blockers on cardiac angiotensinconverting enzyme $2 / \mathrm{C}$. M. Ferrario [et al.] // Circulation. - 2005. - Vol. 111, iss. 20. - P. 2605-2610. - doi:10.1161/ CIRCULATIONAHA.104.510461.

24. New frontiers in the intrarenal Renin-Angiotensin system: a critical review of classical and new paradigms / J. L. Zhuo [et al.] // Frontiers in Endocrinology (Lausanne). 2013. - Vol. 4. - P. 166. - doi: 10.3389/fendo.2013.00166.

25. Receptor recognition by novel coronavirus from Wuhan: An analysis based on decade-long structural studies of SARS / Y. Wan [et al.] // Journal of Virology. - 2020. doi: 10.1128/JVI.00127-20.

26. A crucial role of angiotensin converting enzyme 2 (ACE2) in SARS coronavirus-induced lung injury / K. Kuba [et al.] // Nature Medicine. - 2005. - Vol. 11, iss. 8. - P. 875-879. - doi: $10.1038 / \mathrm{nm} 1267$.

27. Imai, Y. The discovery of angiotensin-converting enzyme 2 and its role in acute lung injury in mice / Y. Imai, K. Kuba, J. M. Penninger // Experimental physiology. - 2008. - Vol. 93, iss. 5. - P. 543-548. - doi: 10.1113/ expphysiol.2007.040048.

28. Channappanavar, R. Pathogenic human coronavirus infections: causes and consequences of cytokine storm and immunopathology / R. Channappanavar, S. Perlman // Seminars in Immunopathology. - 2017. - Vol. 39, iss. 5. P. 529-539. - doi: 10.10 07/s0 0281-017-0629-x.

29. Tveito, K. Cytokine storms in COVID-19 cases / K. Tveito // Tidsskrift for den Norske Legeforening. - 2020. P. 140. - doi: 10.4045/tidsskr.20.0239.

30. Activation of human $\mathrm{T}$ cells in hypertension: studies of humanized mice and hypertensive humans / H. A. Itani [et al.] // Hypertension. - 2016. - Vol. 68, iss. 1. - P. 123-132. - doi: 10.1161/HYPERTENSIONAHA.116.07237.

31. Hypertension and increased endothelial mechanical stretch promote monocyte differentiation and activation: roles of STAT3, interleukin 6 and hydrogen peroxide / R. Loperena [et al.] // Cardiovascular Research. - 2018. - Vol. 114, iss. 11. - P. 1547-1563. - https://doi.org/10.1093/cvr/cvy112.

32. Immune mechanisms of hypertension / G. Drummond [et al.] // Nature Reviews Immunology. - 2019. - Vol. 19, iss. 8. - P. 517-532. - doi: 10.1038/s41577-019-0160-5.

33. Chinese Clinical Guidance for COVID-19 Pneumonia Diagnosis and Treatment [Electronic resource] / China NHCotPsRo. $-7^{\text {th }}$ ed. -2020 . - Mode of access: http:// kjfy.meetingchina.org/msite/news/show/cn/3337.html. Date of access: 22.05.20.

34. IL-6 trans-signalling contributes to aldosterone-induced cardiac fibrosis / C.-H. Chou [et al.] // Cardiovascular Research. - 2018. - Vol. 114, iss. 5. - P. 690-702. - doi: $10.1093 / \mathrm{cvr} / \mathrm{cvy} 013$.

35. Reduction and functional exhaustion of $\mathrm{T}$ cells in patients with coronavirus disease 2019 (covid-19) [Electronic resource] / B. Diao [et al.] // MedRxiv. - 2020. - Mode of access: www.medrxiv.org/content/10.1101/2020.02.18. 20024364v1. - Date of access: 22.15.20. - doi:10.1101/20 20.02.18.20024364.

36. White blood cells and blood pressure: A Mendelian Randomization Study / M. Siedlinski [et al.] // Circulation. - 2020. - 2020. - Vol. 141, iss. 16. - P. 1307-1317. doi:10.1161/CIRCULATIONAHA.119.045102.

37. Patients taking ACE-i and ARBs who contract COVID-19 should continue treatment, unless otherwise advised by their physician: Statement [Electronic resource] / American Heart Association, Heart Failure Society of America, American College of Cardiology // Newsroom. - Mode of access: https://newsroom.heart.org/ news/patients-takingace-i-and-arbs-who-contract-covid-19-should-continuetreatment-unless-otherwise-advised-by-their-physician. Date of access: 20.05.20.

38. Renin-Angiotensin-Aldosterone System Inhibitors in Patients with Covid 19 / M. Vaduganathan [et al.] // New England Journal of Medicine. - 2020. - Vol. 382, iss. 17. P. 1653-1659. - doi: 10.1056 / NEJMsr2005760.

39. Angiotensin II Receptor Blockers and AngiotensinConverting Enzyme Inhibitors Usage is Associated with Improved Inflammatory Status and Clinical Outcomes in COVID-19 Patients With Hypertension [Electronic resource] / Y. Guang [et al.] // MedRxiv. - 2020. - Mode of access: www.medrxiv.org/content/10.1101/2020.03.31. 20038935v1.full.pdf + html. - Date of access: 22.05.20. https://doi.org/10.1101/2020.03.31.20038935.

40. Association of inpatient use of angiotensin converting enzyme inhibitors and angiotensin II receptor blockers with mortality among patients with hypertension hospitalized with COVID-19 / P. Zhang [et al.] // Circulation Research. - 2020. - Vol. 126, iss. 12. - P. 1671-1681. - doi: 10.1161/ CIRCRESAHA.120.317134.

41. Renin-Angiotensin-Aldosterone System Blockers and the Risk of Covid-19 / G. Mancia [et al.] // New England Journal of Medicine. - 2020. - Vol. 382. - P. 2431-2440. - doi: 10.1056/NEJMoa2006923.

42. Renin-Angiotensin-Aldosterone System Inhibitors and Risk of Covid-19 / H. Reynolds [et al.] // New England Journal of Medicine. 2020. - Vol. 382. - P. 2441-2448. doi: 10.1056/NEJMoa2008975.

43. Cardiovascular Disease, Drug Therapy, and Mortality in Covid-19 / M. R. Mehra [et al.] // New England Journal of Medicine. - 2020. - Vol. 382. - P. e102. - doi: 10.1056/ NEJMoa2007621.

44. ACE2 gene expression is activated in human heart failure / A. B. Goulter [et al.] // BMC. Medicine. - 2004. Vol. 2. - P. 19. - doi: 10.1186/1741-7015-2-19. 
45. Circulating plasma concentrations of angiotensinconverting enzyme 2 in men and women with heart failure and effects of renin angiotensin-aldosterone inhibitors / I. E. Sama [et al.] // European Heart Journal. - 2020. Vol. 41 (19). - P. 1810-1817. - doi:10.1093/eurheartj/ ehaa373.

46. Onder, G. Case-fatality rate and characteristics of patients dying in relation to COVID-19 in Italy / G. Onder, G. Rezza, S. Brusaferro // JAMA. - 2020. - Vol. 323, iss. 18 - P. 1775-1776. - doi: 10.1001/jama.2020.4683.

47. Angiotensin-converting enzyme2 (ACE2) as a SARSCoV-2 receptor: molecular mechanisms and potential therapeutic target / H. Zhang [et al.] // Intensive Care Medicine. - 2020. - Vol. 46 (4). - P. 586-590. - doi: 10.1007/s00134-020-05985-9.

48. Coronavirus disease 2019 (COVID-19): do angiotensinconverting enzyme inhibitors/angiotensin receptor blockers have a biphasic effect / R. Sommerstein [et al.] // Journal of the American Heart Association. - 2020. - Vol 9, iss. 7. - P. e016509. - doi:10.1161/JAHA.120.016509.

49. Inhibition of SARS-CoV-2 Infections in Engineered Human Tissues Using Clinical-Grade Soluble Human ACE2 / V. Monteil [et al.] // Cell. - 2020. - Vol. 181, iss. 4. - P. 905-913. - doi: 10.1016/j.cell.2020.04.004.

50. Novel therapeutic approaches targeting the reninangiotensin system and associated peptides in hypertension and heart failure / L. B. Arendse [et al.] // Pharmacological Reviews. - 2019. - № 71 (4). - P. 539-570. - doi: 10.1124/ pr.118.017129.

\section{References}

1. Stanaway JD, Afshin A, Gakidou E, Lim SS, Abate D, Abate KH, Abbafati C, Abbasi N, Abbastabar H, Abd-Allah F, Abdela J, Abdelalim A, Abdollahpour L, Abdulkader RS, Abebe M, Abebe Z, Abera SF, Abil OZ, Abraha HN, Abrham AR, Abu-Raddad LJ, Abu-Rmeileh NM, Accrombessi MMK, Acharya D, Acharya P, et al. Global, regional, and national comparative risk assessment of 84 behavioural, environmental and occupational, and metabolic risks or clusters of risks for 195 countries and territories, 1990-2017: a systematic analysis for the Global Burden of Disease Study 2017. Lancet. 2018;392(10159):1923-1994. doi: 10.1016/S0140-6736(18)32225-6.8.

2. Mills KT, Bundy JD, Kelly TN, Reed JE, Kearney PM, Reynolds K, Chen J, He J. Global Disparities of Hypertension Prevalence and Control: A Systematic Analysis of Population-based Studies from 90 Countries. Circulation. 2016. 134(6):441-450. doi: 10.1161/ CIRCULATIONAHA.115.018912.

3. Adhikari SP, Meng S, Wu Y-J, Mao Y-P, Ye R-X, Wang Q-Z, Sun C, Sylvia S, Rozelle S, Raat H, Zhou H. Epidemiology, causes, clinical manifestation and diagnosis, prevention and control of coronavirus disease (COVID-19) during the early outbreak period: a scoping review. Infectious Diseases of Poverty. 2020;9(1):29. doi: 10.1186/s40249-020-00646-x.

4. Sifuentes-Rodríguez E, Palacios-Reyes D. COVID-19: The outbreak caused by a new coronavirus. Boletin medico del Hospital Infantil de Mexico. 2020;77(2):47-53. doi:10.24875/BMHIM.20000039.

5. Wu D, Wu T, Liu Q, Yang Z. The SARS-CoV-2 outbreak: what we know. International Journal of Infectious Diseases. 2020;94:44-48. doi: 10.1016/j.ijid.2020.03.004.

6. Kreutz R, El-Hady Algharably EA, Azizi M, Dobrowolski P, Guzik T, Januszewicz A, Persu A, Prejbisz A, Riemer TG, Wang J-G, Burnie M. Hypertension, the renin-angiotensin system, and the risk of lower respiratory tract infections and lung injury: implications for COVID-19. Cardiovascular Research. 2020;cvaa097. doi: 10.1093/ cvr/cvaa097.

7. Madjid M, Safavi-Naeini P, Solomon SD, Vardeny O. Potential Effects of Coronaviruses on the Cardiovascular System: A Review. JAMA Cardiology. 2020. doi: 10.1001/ jamacardio.2020.1286.

8. Wang Z, Chen Z, Zhang L, Wang X, Hao G, Zhang Z, Shao L, Tian Y, Dong Y, Zheng C, Wang J, Zhu M, Weintraub WS, Gao R. Status of hypertension in China: results from the China Hypertension Survey. 2012-2015. Circulation. 2018;137(22):2344-2356. doi: 10.1161/ CIRCULATIONAHA.117.032380.

9. Bai SL, Wang JY, Zhou YQ, Yu DS, Gao XM, Li LL, Yang F. The epidemiological characteristics of an outbreak of 2019 novel coronavirus diseases (COVID-19) in China. Zhonghua Liu Xing Bing Xue Za Zhi. 2020;41(2):145-151. doi: 10.3760/cma.j.issn.0254-6450.2020.02.003.

10. Singh AK, Gupta R, Misra A. Comorbidities in COVID-19: Outcomes in hypertensive cohort and controversies with renin angiotensin system blockers. Diabetology \& Metabolic Syndrome. 2020;14(4):283-287. doi: 10.1016/j. dsx.2020.03.016.

11. Guan W-j, Ni Z-y, Hu Y, Liang W-h, Ou C-q, He J-x, Liu L, Shan H, Lei C-1, Hui DSC, Du B, Li L-j, Zeng G, Yuen K-Y, Chen R-c, Tang C-1, Wang T, Chen P-y, Xiang J, Li S-y, Wang J-1, Liang Z-j, Peng Y-x, Wei L, Liu Y, et al. Clinical characteristics of coronavirus disease 2019 in China. New England Journal of Medicine. 2020;382:17081720. doi: 10.1056/NEJMoa2002032.

12. Zhang J-j, Dong X, Cao YY, Yuan Y-D, Yang Y-B, Yan Y-Q, Akdis CA, Gao Y-D. Clinical characteristics of 140 patients infected by SARS-CoV-2 in Wuhan, China. Allergy. 2020 Jul;75(7):1730-1741. doi: 10.1111/ all.14238.

13. Garg S, Kim L, Whitaker M, O'Halloran A, Cummings C, Holstein R, Prill M, Chai SJ, Kirley PD, Alden NB, Kawasaki B, Yousey-Hindes K, Niccolai L, Anderson EJ, Openo KP, Weigel A, Monroe ML, Ryan P, Henderson J, Kim S, Como-Sabetti K, Lynfield R, Sosin D, Torres S, Muse A, et al. Hospitalization Rates and Characteristics of Patients Hospitalized with Laboratory-Confirmed Coronavirus Disease 2019 - COVID-NET, 14 States, March 1-30, 2020. Morbidity and Mortality Weekly Report. 2020;69(15):458-464. doi: 10.15585/mmwr.mm6915e3.

14. Tocci G, Nati G, Cricelli C, Parretti D, Lapi F, Ferrucci A, Borghi C, Volpe M. Prevalence and control of hypertension in the general practice in Italy: updated analysis of a large database. Journal of Human Hypertension. 2017;31(4):258-262. doi: 10.1038/jhh.2016.71.

15. Richardson S, Hirsch JS, Narasimhan M, Crawford JM, McGinn T, Davidson KW. Presenting Characteristics, Comorbidities, and Outcomes Among 5700 Patients Hospitalized With COVID-19 in the New York City Area. JAMA. 2020;323(20):2052-2059. doi: 10.1001/ jama.2020.6775.

16. Paul M, Mehr AR, Kreutz R. Physiology of local renin-angiotensin systems. Physiological Reviews. 2006;86(3):747803. doi: 10.1152/physrev.00036.2005.

17. Romero C, Orias M, Weir M. Novel RAAS agonists and antagonists: clinical applications and controversies. Nature Reviews Endocrinology. 2015;11(4):242-252. doi: 10.1038/nrendo.2015.6.

18. Ferrario $\mathrm{CM}$, Mullick AE. Renin angiotensin aldosterone inhibition in the treatment of cardiovascular disease. Pharmacology Research. 2017;125(Pt A):57-71. doi: 
10.1016/j.phrs.2017.05.020.

19. Jakubova LV, Kezhun LV, Semyachkina-Glushkovskaya OV. Izmenenie aktivnosti renina plazmyi funkcii jendotelija u lic s arterialnoj gipertenziej pri terapii s vkljucheniem ingibitora angiotenzinprevrashhajushhego fermenta i holekalciferola [Changes in plasma renin activity and endothelial function in patients with arterial hypertension with inclusion in therapy inhibitor of angiotensin-converting enzyme and cholecalciferol]. Recept [Recipe]. 2017;20(6):568-577. (Russian).

20. Kezhun LV, Yankovskaya LV. Rol renin-angiotenzin-aldosteronovoj sistemy i vitamina D v razvitii arterialnoj gipertenzii $\mathrm{u}$ zhenshhin $\mathrm{v}$ perimenopauzalnom periode [Role of renin-angiotensin-aldosterone system and vitamin $\mathrm{D}$ in development of arterial hypertension in perimenopausal women]. Zhurnal Grodnenskogo gosudarstvennogo medicinskogo universiteta [Journal of the Grodno State Medical University]. 2013;1(41):14-17. (Russian).

21. Kezhun LV, Yankouskaya LV. Aktivnost renina plazmy funkcii jendotelija i status vitamina $\mathrm{D}$ zhenshhin s arterialnoj gipertenziej v premenopauzalnom i rannem postmenopauzalnom periodah [Plasma renin activity endothelial function and vitamin D status in women with hypertension in the premenopausal and early postmenopausal periods]. Zhurnal Grodnenskogo gosudarstvennogo medicinskogo universiteta [Journal of the Grodno State Medical University]. 2014;4(48):37-42. (Russian).

22. Dinh DT, Frauman AG, Johnston CI, Fabiani ME. Angiotensin receptors: distribution, signaling and function. Clinical Science. 2001;100(5):481-492.

23. Ferrario CM, Jessup JA, Chappell MC, Averill DB, Brosnihan KB, Tallant EA, Diz DI, Gallagher PE. Effect of angiotensin-converting enzyme inhibition and angiotensin II receptor blockers on cardiac angiotensin-converting enzyme 2. Circulation. 2005;111(20):2605-2610. doi:10.1161/CIRCULATIONAHA.104. 510461.

24. Zhuo JL, Ferrao FM, Zheng Y, Li XC. New frontiers in the intrarenal Renin-Angiotensin system: a critical review of classical and new paradigms. Frontiers in Endocrinology (Lausanne). 2013;4:166. doi: 10.3389/fendo.2013.00166.

25. Wan Y, Shang J, Graham R, Baric RS, Li F. Receptor recognition by novel coronavirus from Wuhan: An analysis based on decade-long structural studies of SARS. Journal of Virology. 2020. doi: 10.1128/JVI.00127-20.

26. Kuba K, Imai Y, Rao S, Gao H, Guo F, Guan B, Huan Y, Yang P, Zhang Y, Deng W, Bao L, Zhang B, Liu G, Wang Z, Chappell M, Liu Y, Zheng D, Leibbrandt A, Wada T, Slutsky AS, Liu D, Qin C, Jiang C, Penninger JM. A crucial role of angiotensin converting enzyme 2 (ACE2) in SARS coronavirus-induced lung injury. Nature Medicine. 2005;11(8):875-879. doi: 10.1038/nm1267.

27. Imai Y, Kuba K, Penninger JM. The discovery of angiotensin-converting enzyme 2 and its role in acute lung injury in mice. Experimental physiology. 2008;93(5):543-548. doi: 10.1113/expphysiol.2007.040048.

28. Channappanavar R, Perlman S. Pathogenic human coronavirus infections: causes and consequences of cytokine storm and immunopathology. Seminars in Immunopathology. 2017;39(5):529-539. doi: 10.10 07/s0 0281-017-0629-x.

29. Tveito K. Cytokine storms in COVID-19 cases? Tidsskrift for den Norske Legeforening. 2020 Mar 23;140. doi: 10.4045/tidsskr.20.0239.

30. Itani HA, McMaster WG, Saleh MA, Nazarewicz RR, Mikolajczyk TP, Kaszuba AM, Konior A, Prejbisz A, Januszewicz A, Norlander AE, ChenW, Bonami RH, Marshall AP, Poffenberger G, Weyand CM, Madhur MS,
Moore DJ, Harrison DG, Guzik TJ. Activation of human $\mathrm{T}$ cells in hypertension: studies of humanized mice and hypertensive humans. Hypertension. 2016;68(1):123-132. doi: 10.1161/HYPERTENSIONAHA.116.07237.

31. Loperena R, Van Beusecum JP, Itani HA, Engel N, Laroumanie F, Xiao L, Elijovich F, Laffer CL, Gnecco JS, Noonan J, Maffia P, Jasiewicz-Honkisz B, CześnikiewiczGuzik M, Mikolajczyk TP, Śliwa T, Dikalov S, Weyand CM, Guzik TJ, Harrison DG. Hypertension and increased endothelial mechanical stretch promote monocyte differentiation and activation: roles of STAT3, interleukin 6 and hydrogen peroxide. Cardiovascular Research. 2018;114(11):1547-1563. https://doi.org/10.1093/cvr/ cvy112.

32. Drummond GR, Vinh A, Guzik TJ, Sobey CG. Immune mechanisms of hypertension. Nature Reviews Immunology. 2019;19(8):517-532. doi: 10.1038/s41577-019-0160-5.

33. China NHCotPsRo. Chinese Clinical Guidance for COVID-19 Pneumonia Diagnosis and Treatment [Internet]. $7^{\text {th }}$ ed. 2020. Available from: http://kjfy.meetingchina.org/ msite/news/show/cn/3337.html.

34. Chou C-H, Hung C-S, Liao C-W, Wei L-H, Chen C-W, Shun C-T, Wen W-F, Wan C-H, Wu X-M, Chang Y-Y, Wu V-C, Wu K-D, Lin Y-H. IL-6 trans-signalling contributes to aldosterone-induced cardiac fibrosis. Cardiovascular Research. 2018;114(5):690-702. doi: 10.1093/cvr/cvy013.

35. Diao B, Wang C, Tan Y, Chen X, Liu Y, Ning L, Chen L, Li M, Liu Y, Wang G, Yuan Z, Feng Z, Wu Y, Chen Y. Reduction and functional exhaustion of $T$ cells in patients with coronavirus disease 2019 (covid-19) [Internet]. MedRxiv. 2020. Available from: www.medrxiv.org/conte $\mathrm{nt} / 10.1101 / 2020.02 .18 .20024364 \mathrm{v} 1$. doi:10.1101/2020.02 .18 .20024364 .

36. Siedliński M, Józefczuk E, Xu X, Teumer A, Evangelou E, Schnabel RB, Welsh P, Maffia P, Erdmann J, Tomaszewski M, Caulfield MJ, Sattar N, Holmes MV, Guzik TJ. White blood cells and blood pressure: A Mendelian Randomization Study. Circulation. 2020;141(16):13071317. doi:10.1161/CIRCULATIONAHA. 119.045102.

37. American Heart Association, Heart Failure Society of America, American College of Cardiology. Patients taking ACE-i and ARBs who contract COVID-19 should continue treatment, unless otherwise advised by their physician: Statement. [Internet]. Newsroom. Available from: https:// newsroom.heart.org/news/patients-taking-ace-i-and-arbswho-contract-covid-19-should-continue-treatment-unlessotherwise-advised-by-their-physician.

38. Vaduganathan $M$, Vardeny $O$, Pharm $D$, Michel $T$, McMurray JJ, Pfeffer MA, Solomon SD. ReninAngiotensin-Aldosterone System Inhibitors in Patients with Covid 19. New England Journal of Medicine. 2020;382(17):1653-1659. doi: 10.1056 /NEJMsr2005760.

39. Yang G, Tan Z, Zhou L, Yang M, Peng L, Liu J, Cai J, Yang R, Han J, Huang Y, He S. Angiotensin II Receptor Blockers and Angiotensin-Converting Enzyme Inhibitors Usage is Associated with Improved Inflammatory Status and Clinical Outcomes in COVID-19 Patients with Hypertension [Internet]. MedRxiv. 2020. Available from: https://www. medrxiv.org/content/10.1101/2020.03.31.20038935v1. full.pdf+html. doi: https://doi.org/10.1101/2020.03.31.20 038935.

40. Zhang P, Zhu L, Cai J, Lei F, Qin Z, Xie J, Liu EM, KiZhao Y, Huang X, Lin L, Xia M, Chen MM, Cheng X, Zhang X, Guo D, Peng Y, Xiao-Ji, Chen J, She ZG, Wang Y, Xu Q, Tan R, Wang H, Ling J, Luo P, et al. Association of inpatient use of angiotensin converting enzyme inhib- 
itors and angiotensin II receptor blockers with mortality among patients with hypertension hospitalized with COVID-19. Circulation Research. 2020;126(12):16711681. doi: 10.1161/CIRCRESAHA.120. 317134.

41. Mancia G, Rea F, Ludergnani M, Apolone G, Corrao G. Renin-Angiotensin-Aldosterone System Blockers and the Risk of Covid-19. New England Journal of Medicine. 2020;382:2431-2440. doi: 10.1056/NEJMoa2006923.

42. Reynolds HR, Adhikari S, Pulgarin C, Troxel AB, Iturrate E, Johnson SB, Hausvater A, Newman JD, Berger JS, Bangalore S, Katz SD, Fishman GI, Kunichoff D, Chen Y, Ogedegbe G, Hochman JS. Renin-AngiotensinAldosterone System Inhibitors and Risk of Covid-19. New England Journal of Medicine. 2020;382:2441-2448. doi: 10.1056/NEJMoa2008975.

43. Mehra MR, Desai SS, Kuy SR, Henry TD, Patel AN. Cardiovascular Disease, Drug Therapy, and Mortality in Covid-19. New England Journal of Medicine. 2020;382:e102. doi: 10.1056/NEJMoa2007621.

44. Goulter AB, Goddard MJ, Allen JS, Kenneth CL. ACE2 gene expression is activated in human heart failure. $B M C$. Medicine. 2004;2:19. doi: 10.1186/1741-7015-2-19.

45. Sama IE, Ravera A, Santema BT, van Goor H, ter Maaten JM, Cleland JGF, Rienstra M, Friedrich AW, Samani NJ, Ng LL, Dickstein K, Lang CC, Filippatos G, Anker SD, Ponikowski P, Metra M, van Veldhuisen D, Voors AA. Circulating plasma concentrations of angiotensinconverting enzyme 2 in men and women with heart failure and effects of renin angiotensin-aldosterone inhibitors. European Heart Journal. 2020;41(19):1810-1817. doi:10.1093/eurheartj/ehaa373.
46. Onder G, Rezza G, Brusaferro S. Case-fatality rate and characteristics of patients dying in relation to COVID-19 in Italy. JAMA. 2020;323(18):1775-1776. doi: 10.1001/ jama.2020.4683.

47. Zhang H, Penninger JM, Li Y, Zhong N, Slutsky AS. Angiotensin-converting enzyme2 (ACE2) as a SARS$\mathrm{CoV}-2$ receptor: molecular mechanisms and potential therapeutic target. Intensive Care Medicine. 2020;46(4):586590. doi: 10.1007/s00134-020-05985-9.

48. Sommerstein R, Michael MK, Franz HM, Christoph G. Coronavirus disease 2019 (COVID-19): do angiotensin-converting enzyme inhibitors/angiotensin receptor blockers have a biphasic effect? Journal of the American Heart Association. 2020;9(7):e016509. doi: 10.1161/ JAHA.120.016509.

49. Monteil V, Kwon H, Prado P, Hagelkrüys A, Wimmer RA, Stahl M, Leopoldi A, Garreta E, Hurtado C, del Pozo CH, Prosper F, Romero JP, Wirnsberger G, Zhang H, Slutsky AS, Conder R, Montserrat N, Mirazimi A, Penninger JM. Inhibition of SARS-CoV-2 Infections in Engineered Human Tissues Using Clinical-Grade Soluble Human ACE2. Cell. 2020;181(4):905-913. doi: 10.1016/j. cell.2020.04.004.

50. Arendse LB, Jan Danser AH, Poglitsch M, Touyz RM, Burnett JC, Llorens-Cortes C, Ehlers M, Sturrock ED. Novel therapeutic approaches targeting the renin-angiotensin system and associated peptides in hypertension and heart failure. Pharmacological Reviews. 2019;71(4):539-570. doi: 10.1124/pr.118.017129.

\section{CLINICAL ASSOCIATIONS BETWEEN CORONAVIRUS INFECTION (COVID-19) AND ARTERIAL HYPERTENSION: PATHOGENETIC MECHANISMS AND DISCUSSION ON THE USE OF INHIBITORS OF THE RENIN-ANGIOTENSIN-ALDOSTERONE SYSTEM Yakubava L. V., Kezhun L. V., Snezhitskiy V. A. Grodno State Medical University, Grodno, Belarus}

A review of current publications suggests that patients with arterial hypertension (AH) are at increased risk for severe course and fatal outcome of COVID-19. The main pathogenetic mechanisms explaining the association of AH with COVID-19 include the effect of coronavirus on the functioning of the renin-angiotensin-aldosterone system (RAAS), which is involved in the development and progression of AH. The review presents the results of a number of studies evaluating the effect of the use of ACE inhibitors / ARBs on the development and course of COVID-19 in patients with cardiovascular diseases. The results of international data analysis showed that the use of ACE inhibitors / ARBs in patients with AH and COVID-19 is associated with lower rates of total mortality, and the use of ACE inhibitors, statins and the female sex are associated with a greater likelihood of patient survival. The data on the promising development of new drugs affecting the functioning of RAAS are presented.

Keywords: COVID-19, arterial hypertension, renin-angiotensin-aldosterone system

For citation: Yakubava LV, Kezhun LV, Snezhitskiy VA. Clinical associations of coronavirus infection COVID-19 and arterial hypertension: pathogenetic mechanisms and discussion of the use of inhibitors of the reninangiotensin-aldosterone system. Journal of the Grodno State Medical University. 2020;18(4):349-357. http://dx.doi. org/10.25298/2221-8785-2020-18-4-349-357.

Конфликт интересов. Авторы заявляют об отсутствии конфликта интересов.

Conflict of interest. The authors declare no conflict of interest.

Об авторах / About the authors

* Якубова Людмила Валерьевна / Jakubava Ljudmila , e-mail: yankovliuda@yandex.by, ORCID: 0000-0001-7632-9695

Кежун Людмила Васильевна / Kezhun Ljudmila, e-mail: kezhun.liudmila@yandex.by, ORCID: 0000-0002-0244-5623

Снежицкий Виктор Александрович / Snezhitskiy Viktor, e-mail: snezh@grsmu.by, ORCID: 0000-0002-1706-1243

* - автор, ответственный за переписку / corresponding author 